\title{
Research and Analysis on the Index System of Digital Economy in Anhui Province
}

\author{
Zhong Wang $\mathbb{D}^{1,2}$ and Peibei Shi $\mathbb{D}^{1}$ \\ ${ }^{1}$ School of Computer Science and Technology, Hefei Normal University, Hefei 230601, China \\ ${ }^{2}$ School of Computer Science and Technology, University of Science and Technology of China, Hefei 230026, China \\ Correspondence should be addressed to Peibei Shi; pb_shi@163.com
}

Received 7 March 2021; Revised 28 March 2021; Accepted 30 March 2021; Published 9 April 2021

Academic Editor: Shaohui Wang

Copyright $\odot 2021$ Zhong Wang and Peibei Shi. This is an open access article distributed under the Creative Commons Attribution License, which permits unrestricted use, distribution, and reproduction in any medium, provided the original work is properly cited.

\begin{abstract}
The development of the digital economy is of special significance to the realization of the stable development of the macroeconomy. Based on the White Paper on Development of China's Digital Economy and the actual situation of cities in Anhui Province, this study divides the index system of digital economy into three primary indexes, namely, digital industrialization, industrial digitization, and information infrastructure, and 20 secondary indexes. The percentage weight of each index is determined by the subjective evaluation method, and the index values of 16 cities in Anhui Province are calculated according to the efficacy coefficient method. Then, the mean value, standard deviation, variance, kurtosis, skewness, and other information of each index system are statistically analyzed, and the policy suggestions for the development of digital economy are given. This study fills the blank of the index system of digital economy in Anhui Province and has a certain role in promoting the development of digital economy in Anhui Province.
\end{abstract}

\section{Introduction}

Digital economy is a series of economic activities that use digital knowledge and information as key production factors, modern information network as an important carrier, and the effective use of information and communication technology as an important driving force for efficiency improvement and economic structure optimization. The 2018 China Network Security and Information Work Conference pointed out that it is necessary to develop the digital economy, accelerate the promotion of digital industrialization, rely on information technology innovation, and use new kinetic energy to promote new development. In the current macroeconomic environment of our country, it is of special significance to develop digital economy and give full play to the role of digital economy platform for the stable development of macroeconomy [1].

The measurement and accounting of digital economy is an important foundation and support to strengthen the development management of digital economy and promote the development of digital economy [2]. The existing traditional measurement methods cannot measure the digital economy scientifically, and the statistical index system that adapts to the characteristics of digital economy needs to be established. There is no unified standard for the index system of digital economy at home and abroad [3]. The research on the measurement of the development of digital economy mainly focuses on qualitative description. Even some scholars only construct the evaluation index system of the development of digital economy, which cannot provide a method to measure the digital economy quantitatively. Moreover, the existing quantitative research is mostly limited to using simple descriptive statistical analysis or the structural equation model. Quantitative analysis, lack of objective, comprehensive, and systematic quantitative research results cannot timely and accurately reflect the current situation of China's digital economy development [4].

This study takes the digital China White Paper as the guiding direction and combines the actual conditions of 
various cities in Anhui Province to divide the digital economy indicator system into three primary indicators and 20 secondary indicators: digital industrialization, industrial digitization, and information infrastructure. The subjective assignment method is used to determine the percentage weight of each indicator, and the indicator values of 16 cities in Anhui Province are calculated according to the efficiency coefficient method, and then, the mean, standard deviation, variance, kurtosis, skewness, and other information of each indicator system are statistically analyzed, and the policy suggestions for the development of digital economy are given. The rest of the content is arranged as follows. Section 2 introduces related works, Section 3 focuses on the construction and weight design of the digital economy indicator system, and Section 4 gives the statistical analysis results of each indicator system and provides statistics on various cities in Anhui Province economic analysis and finally gives a summary and outlook.

\section{Related Works}

The European Union has always attached great importance to the development and statistics of the digital economy [5]. Since 2014, it has published the EU digital economy and society report and the digital economy and society index (DESI). DESI is a composite index describing the development degree of digital economy in EU countries [6]. The index is calculated by 31 secondary indicators of broadband access, human capital, Internet application, digital technology application, and digital public service degree in EU countries [7]. In 2016, the digital economy Advisory Committee of the US Department of Commerce proposed in the first report of the digital economy committee to measure the impact of digitization on economic indicators (such as GDP and productivity level) and the expansion effect of digitization on cross industry and put forward four subframeworks to measure the digital economy [8]. As an early research institution on digital economy, OECD official publication Internet economy outlook has a longterm follow-up and forward-looking research on digital economy. It conducts preliminary research on digital economy from the perspective of the direct method and puts forward six major areas that should be focused on in establishing new measurement standards. The World Economic Forum (WEF) has published the network readiness index (NRI) since 2002, which focuses on the ranking, main experience, and practices of the leading countries and regions in the global informatization field [9-11]. NRI is quite authoritative in the international evaluation of informatization field. Although there are many third level indicators (53), the first and second level indicators are very concise and scientific. Since 1995, the United Nations International Telecommunication Union has released the 9 th edition of the report on measuring the information society and the ICT development index (IDI), which has long-term research accumulation and professionalism [12]. In 2017, the evaluation objects include 176 economies in the world, which are widely used by governments and departments [13].
It can be seen from the above that the international and domestic index systems have their own strengths and characteristics. In the research results of international institutions, from the perspective of the concept definition and theoretical system construction of digital economy, the U.S. Department of Commerce has studied the definition, theory, scope, and measurement steps of digital economy, which is worthy of reference [14]. From the perspective of index system construction, the EU's digital economic and social index is the most objective and comprehensive, especially in the perspective of data acquisition $[15,16]$. The EU has a large number of relevant surveys and statistical studies, which provide a good research foundation. The EU's longterm and large-scale survey and statistics work mechanism is worth learning. From the perspective of the scientificity and continuity of index design, the network readiness index of the world economic forum and the ICT development index of the International Telecommunication Union of the United Nations have experienced a long test, especially in the measurement and international comparison of information infrastructure and information industry [17].

Compared with many international index systems, China's existing index system has very distinctive characteristics [18]. The first is the new time. The domestic digital economy index was published in 2017 for the first time, showing the importance and rapid response of different institutions, enterprises, and local governments to the national strategy and the development trend of digital economy. However, it also shows that China started late in measuring the development of digital economy. Second, there are strong differences. The measurement methods of international organizations are very standard. The content of the study is nothing more than the basis, application, and influence of digital economy $[19,20]$. China's index has its own characteristics, reflecting the differences of concerns and ideas of different institutions and roles on digital economy. The third is the innovation and application of big data. The enterprise led design index system reflects the diversity of data sources [21].

\section{Methodology}

At the national level, there are mainly four data sources involved in the development of digital economy: China Statistical Yearbook, China Electronic Industry Yearbook, China Electronic Information Industry Statistical Yearbook, and 1949-2009 China Electronic Information Industry Statistics; China fixed investment statistical yearbook and China fixed investment statistical yearbook 1950-2000; and the whole country and local governments A series of inputoutput tables. The first category is comprehensive macrodata, the second and third categories are industry statistics, and the last category is national accounts (SNA) data.

According to the characteristics and development trend of digital economy in Anhui Province, it is found that the statistical data of cities in Anhui Province is much less than that of the national level. According to the feasibility of obtaining data and the actual availability of indicators, the evaluation index system of developing digital economy is 
established, including three primary indicators of digital industrialization, industrial digitization, and infrastructure.

$$
\begin{aligned}
Y_{1} & =\mathrm{HA}_{\mathrm{it}} f\left(\mathrm{EIM}_{\mathrm{it}}, \mathrm{SOFT}_{\mathrm{it}}, \mathrm{TB}_{\mathrm{it}}, \mathrm{INTER}_{\mathrm{it}}, \mathrm{ICM}_{\mathrm{it}}, \mathrm{IIFAI}_{\mathrm{it}}, \mathrm{TI}_{\mathrm{it}}\right), \\
Y_{2} & =\mathrm{HA}_{\mathrm{it}} f\left(\mathrm{EI}_{\mathrm{it}}, \mathrm{SI}_{\mathrm{it}}, \mathrm{EC}_{\mathrm{it}}, \mathrm{WE}_{\mathrm{it}}, \mathrm{WM}_{\mathrm{it}}, \mathrm{WT}_{\mathrm{it}}\right), \\
Y_{3} & =\mathrm{HA}_{\mathrm{it}} f\left(\mathrm{II}_{\mathrm{it}}\right) \\
Y & =\alpha Y_{1}+\beta Y_{2}+\gamma Y_{3},
\end{aligned}
$$

where $Y_{1}$ represents the digital industrialization, $Y_{2}$ represents the industrial digitalization, and $Y_{3}$ represents the infrastructure.

The first level index of digital industrialization is divided into electronic information manufacturing industry and its growth rate $\mathrm{EIM}_{\mathrm{it}}$, software service industry and its growth $\mathrm{SOFT}_{\mathrm{it}}$, telecommunication broadcasting transmission and its growth rate $\mathrm{TB}_{\mathrm{it}}$, Internet and its growth $\mathrm{INTER}_{\mathrm{it}}$, and the number of IT and information enterprises and their growth rate $\mathrm{ICM}_{\mathrm{it}}$, proportion of fixed assets investment in IT and information industry in social fixed assets investment EIM $_{i t}$, and technology innovation in IT and digital economy (output/absorption turnover) $\mathrm{TI}_{\text {it }}$ have 13 secondary indicators. The first level index industry digitization is also divided into the integration of enterprise and industrialization $\mathrm{EI}_{\mathrm{it}}$, standard implementation level $\mathrm{SI}_{\mathrm{it}}$, e-commerce development $\mathrm{EC}_{\mathrm{it}}$, wisdom education $\mathrm{WE}_{\mathrm{it}}$, smart medicine $\mathrm{WM}_{\mathrm{it}}$, and smart tourism $\mathrm{WT}_{\mathrm{it}}$ which have six secondary indicators. The primary index information infrastructure only includes one secondary index information infrastructure $\mathrm{II}_{\mathrm{it}}$.

Combined with the actual situation of data available in Anhui Province, the index weight is determined by the expert method, where $\alpha=0.45, \beta=0.4$, and $\gamma=0.15$. The weight design of secondary indicators is given in Table 1.

\section{Experimental Results}

According to the efficiency coefficient method, the score of each city in Anhui Province is calculated, and then, the final score is calculated according to the weight of the index system. According to the principle of multiobjective programming, the efficacy coefficient method determines a satisfactory value and a disallowed value for each evaluation index, with the satisfactory value as the upper limit and the disallowed value as the lower limit. It calculates the degree of each index to achieve the satisfactory value, determines the score of each index, and then evaluates the comprehensive situation of the object by weighted average. Efficacy coefficient refers to the relative position between the actual value of each evaluation index and the allowable variation range of the index. In the process of comprehensive evaluation, we first use the efficacy coefficient to transform the dimensionless measurement of each index, and then use the geometric average method to calculate the total efficacy coefficient of each efficacy coefficient as the whole comprehensive evaluation value.

Suppose $X_{\mathrm{ij}}$ is the score value of the $j$ index value of the $i^{\text {th }}$ city, $x_{\mathrm{ij}}$ is the actual value of index $j$ of the $i^{\text {th }}$ city, $x_{j \max }$ is the maximum value of index $j, x_{j \text { min }}$ is the minimum value of index $j$. The formula of efficacy coefficient method is as follows:

$$
X_{\mathrm{ij}}=0.4 * \frac{x_{\mathrm{ij}}-x_{j \min }}{x_{j \max }-x_{j \min }}+0.6
$$

Each index of each city will be normalized to $60-100$ points. If the subindex score of an individual city is 0 , set the subindex score as 0 according to the actual situation. Table 2 shows the mean, variance, kurtosis, skewness, and other statistical data of all secondary indicators and gives the statistical analysis chart of each indicator.

In order to further analyze the specific situation of digital economy in Anhui Province, this study gives the comprehensive score statistics of digital economy in Anhui Province, as well as the statistical analysis of each index item.

As can be seen from Figure 1, Hefei has the strongest comprehensive strength in the field of digital economy in Anhui Province, which is obviously ahead of other cities. Hefei, as the capital city of Anhui Province, has the leading position in the field of digital economy. In recent years, Hefei municipal government also attaches great importance to the development of digital economy. At present, there are more than 700 digital economy enterprises in Hefei. In 2017, the scale of digital economy accounted for $35.77 \%$ of GDP, slightly higher than the national average of $32.9 \%$, higher than that of Anhui Province, accounting for 26.89\%. Hefei ranks first in Anhui Province in terms of the number of digital economy related enterprises, business income, employees, and other data. Digital economy has increasingly become the new driving force of economic development in Hefei and occupies an important position in the economic development of Hefei. Hefei has the largest number of enterprises in the field of big data application and the fastest growth in the field of artificial intelligence. In the aspect of digital economy industrialization, Hefei focuses on big data, artificial intelligence, integrated circuit, new display, intelligent manufacturing, healthcare, and other fields and actively builds a regional digital economy production and application center. The development of digital economy industry is marching towards the first Echelon city. Wuhu, Chuzhou, and Xuancheng are in the second batch of teams in the field of digital economy in Anhui Province, while Huaibei, Fuyang, and Huainan are the worst. From a regional perspective, most cities in Northern Anhui are in the middle and lower reaches of the digital economy in Anhui Province, while most cities in southern and central Anhui are in the middle and upper reaches of the digital economy in Anhui Province. The regional differences in the comprehensive strength of urban digital economy are closely related to the informatization infrastructure of the city itself. Relatively speaking, the informatization construction in Northern Anhui started late, and the degree of attention is generally less than that in southern Anhui and central Anhui.

As can be seen from Figure 2, Hefei is in the leading position in the score of electronic information in Anhui Province, while Bozhou ranks first in the score of electronic 
TABLE 1: Weights of the second level.

\begin{tabular}{|c|c|c|}
\hline I level & II level & Coefficients (\%) \\
\hline \multirow{13}{*}{ Digital industrialization } & Electronic information manufacturing industry & 3 \\
\hline & Growth of electronic information manufacturing industry & 2 \\
\hline & Software service industry & 2.4 \\
\hline & Growth of software service industry & 1.6 \\
\hline & Telecommunication, broadcasting, and WeChat transmission & 1.2 \\
\hline & Growth of telecommunication, broadcasting, and WeChat transmission & 0.8 \\
\hline & Internet & 2.4 \\
\hline & Growth of internet & 1.6 \\
\hline & Information industry enterprises number & 6 \\
\hline & Growth of information industry enterprises number & 4 \\
\hline & Proportion of fixed assets investment in information industry in social fixed assets investment & 10 \\
\hline & Technological innovation in the field of digital economy (export turnover) & 5 \\
\hline & Technological innovation in the field of digital economy (absorb turnover) & 5 \\
\hline \multirow{6}{*}{ Industry digitalization } & Merge together with informatization and industrialization & 7.5 \\
\hline & Standard implementation level & 7.5 \\
\hline & E-commerce & 15 \\
\hline & Wisdom education & 3.3 \\
\hline & Wisdom medical & 3.3 \\
\hline & Wisdom tourism & 3.4 \\
\hline Infrastructure & Information infrastructure & 15 \\
\hline
\end{tabular}

TABLE 2: Weights of the second level.

\begin{tabular}{|c|c|c|c|c|c|c|}
\hline Level & Coefficients & Mean & $\begin{array}{l}\text { Standard } \\
\text { deviation }\end{array}$ & Variance & Kurtosis & Skewness \\
\hline Electronic information manufacturing industry & 3 & 63.973 & 9.819 & 96.408 & 14.369 & 3.729 \\
\hline Growth of electronic information manufacturing industry & 2 & 71.415 & 8.933 & 79.793 & 7.312 & 2.140 \\
\hline Software service industry & 2.4 & 52.019 & 27.625 & 763.126 & 0.976 & -1.089 \\
\hline Growth of software service industry & 1.6 & 72.368 & 37.166 & 1381.347 & 0.727 & -1.526 \\
\hline Telecommunication, broadcasting, and WeChat transmission & 1.2 & 65.949 & 9.456 & 89.409 & 13.105 & 3.490 \\
\hline $\begin{array}{l}\text { Growth of telecommunication, broadcasting, and WeChat } \\
\text { transmission }\end{array}$ & 0.8 & 84.699 & 12.272 & 150.609 & -0.724 & -0.587 \\
\hline Internet & 2.4 & 55.511 & 29.588 & 875.474 & 0.605 & -1.141 \\
\hline Growth of Internet & 1.6 & 62.368 & 32.653 & 1066.206 & 0.562 & -1.346 \\
\hline Information industry enterprises number & 6 & 65.475 & 9.853 & 97.074 & 11.409 & 3.253 \\
\hline Growth of information industry enterprises number & 4 & 72.115 & 11.584 & 134.178 & 0.978 & 1.306 \\
\hline $\begin{array}{l}\text { Proportion of fixed assets investment in information industry in } \\
\text { social fixed assets investment }\end{array}$ & 10 & 75.668 & 10.744 & 115.439 & 0.185 & 0.820 \\
\hline $\begin{array}{l}\text { Technological innovation in the field of digital economy (export } \\
\text { turnover) }\end{array}$ & 5 & 91.534 & 3.092 & 9.562 & 4.772 & 2.431 \\
\hline $\begin{array}{l}\text { Technological innovation in the field of digital economy (absorb } \\
\text { turnover) }\end{array}$ & 5 & 91.239 & 2.628 & 6.905 & 9.040 & 2.985 \\
\hline Merge together with informatization and industrialisation & 7.5 & 96.539 & 2.365 & 5.591 & 2.032 & -0.948 \\
\hline Standard implementation level & 7.5 & 84.221 & 9.038 & 81.682 & 0.220 & -0.215 \\
\hline E-commerce & 15 & 92.125 & 1.668 & 2.783 & 0.727 & 0.957 \\
\hline Wisdom education & 3.3 & 93.000 & 10.285 & 105.778 & 3.664 & -1.888 \\
\hline Wisdom medical & 3.3 & 91.506 & 1.872 & 3.503 & -0.415 & 0.788 \\
\hline Wisdom tourism & 3.4 & 60.488 & 13.197 & 174.173 & 0.109 & -0.516 \\
\hline Information infrastructure & 15 & 74.205 & 7.168 & 51.378 & 0.580 & 0.438 \\
\hline
\end{tabular}

information growth in Anhui Province. On the whole, the development trend of electronic information industry in Anhui Province is good, and the layout of relevant enterprises in Anhui Province is comprehensive. Taking Hefei as an example, Hefei Economic and Technological Development Zone is the largest electronic information industry base and demonstration base of new industrialized electronic information industry in Anhui Province. In 2017, the output value of electronic information industry in Hefei Economic and Technological Development Zone was about 77.4 billion yuan, and there were 26 industrial enterprises above Designated Size, mainly distributed in the manufacturing and core supporting links of notebook computers and flat panel computers. Hefei Economic and Technological Development Zone has the most complete integrated circuit and electronic information industry chain 


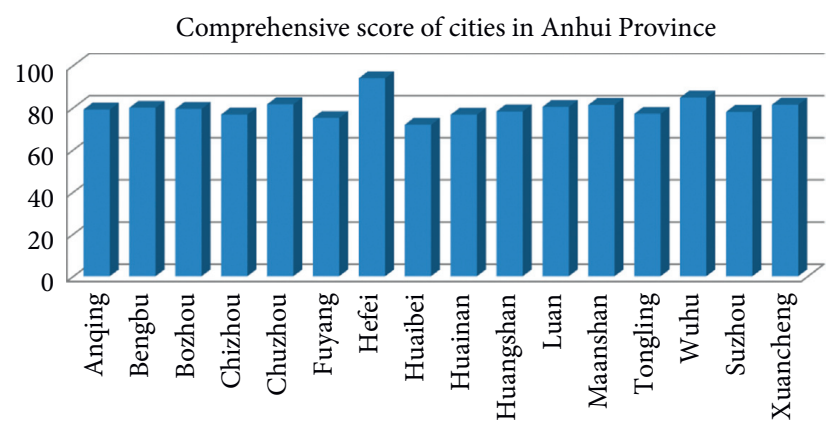

Figure 1: Comprehensive score of cities in Anhui Province.

in central China. It has formed the whole industry chain of complete machine production, parts and components, and supporting links, and its localization supporting level is in the forefront of central China. It has built an electronic information industry base represented by Lianbao Electronics, Baolongda, Jingzhi Electronics, Hangjia Electrical Appliances, Jingwei Electronics, and Xinruida Electronics.

As can be seen from Figure 3, the score of software service industry in Hefei is in the leading position in Anhui Province, and the growth momentum of software service industry in Bengbu, Chizhou, and Hefei ranks first in Anhui Province. Fuyang, Huaibei, and Huangshan have not been deployed in the field of software services and have considerable development potential in the future.

It can be seen from Figure 4 that the scores of Hefei in the fields of telecommunication, broadcasting, and WeChat transmission are significantly higher than those of other cities in the province, which is related to the layout of leading enterprises in related fields in Anhui Province, and most of them are located in Hefei. In terms of telecommunication, broadcasting, and WeChat transmission growth, Xuancheng, Huangshan, Chizhou, and Luan have relatively rapid development momentum.

It can be seen from Figure 5 that Hefei is in the leading position in the field of Internet in Anhui Province, and Anqing city has the fastest growth rate in the field of Internet in Anhui Province. Bozhou, Chizhou, and Huaibei have not yet developed in the field of Internet.

It can be seen from Figure 6 that Hefei is in a leading position in the field of information industry in Anhui Province, and Bozhou is the fastest growing city in the field of information industry in Anhui Province.

It can be seen from Figure 7 that in the proportion of fixed asset investment in information industry in social fixed asset investment, Hefei, Chuzhou, and Tongling are in the top three, while Fuyang and Bozhou are in the backward position in Anhui Province. The proportion of fixed assets investment in information industry in social fixed assets investment to a certain extent reflects the degree of local informatization. The traditional industries in Northern Anhui have a deep foundation, modern information enterprises are less settled, and the investment of fixed assets is less than other traditional industries.

As can be seen from Figure 8, Hefei and Wuhu are obviously ahead of other cities in technological innovation in

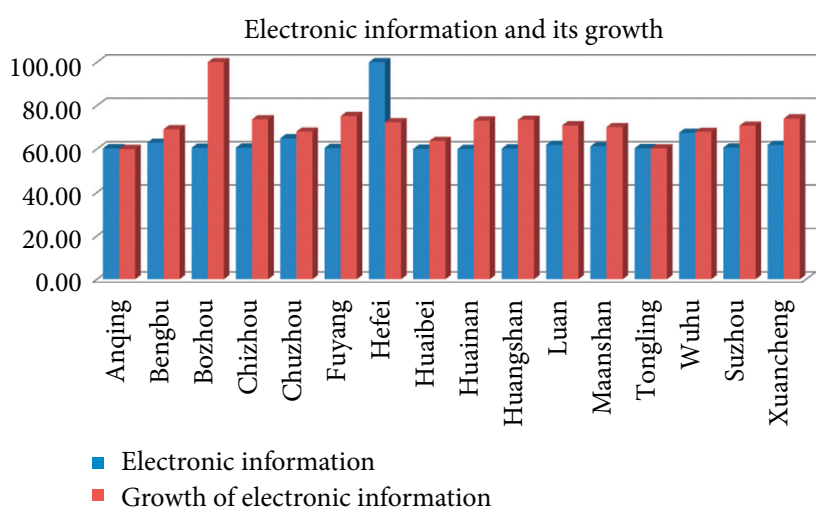

FIGURE 2: Electronic information and its growth.

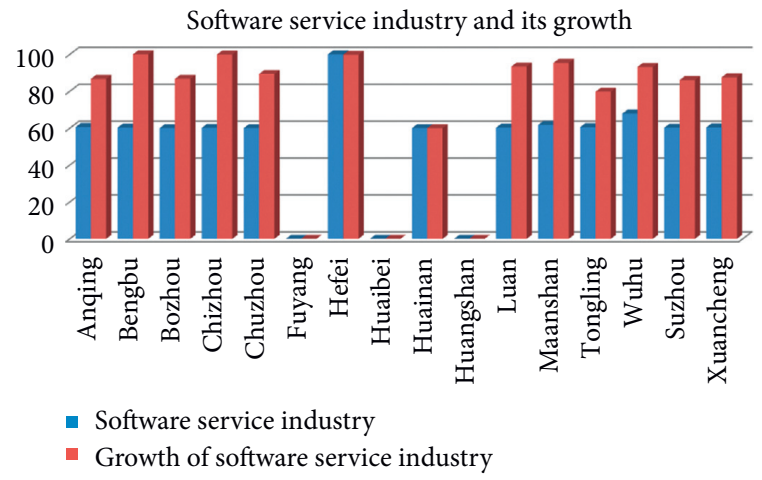

FIGURE 3: Software service industry and its growth.

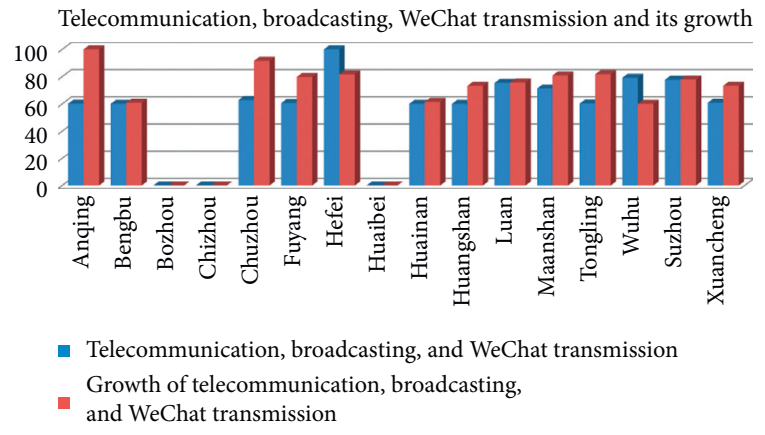

Figure 4: Telecommunication, broadcasting, and WeChat transmission and its growth.

the field of digital economy. Technological innovation needs high-level talents. Hefei and Wuhu have more talents in universities and enterprises than other cities. Hefei is a member city of the world science and technology cities alliance, a national science and technology innovation pilot city, and a comprehensive national science center of China. Relying on the team of University of Science and Technology of China, Wuhu Smart City Research Institute has also made breakthroughs in the field of technological innovation, and its talent reserve is second only to Hefei in Anhui Province.

As can be seen from Figure 9, Hefei is in the leading position in Anhui Province in the development level and 


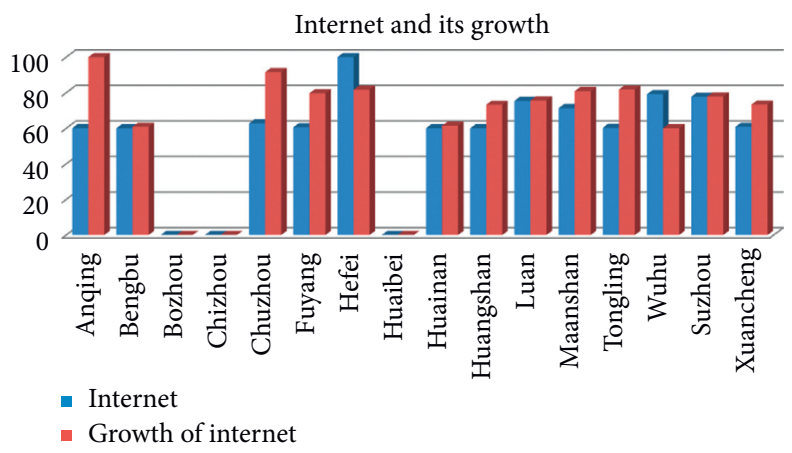

FIGURE 5: Internet and its growth.

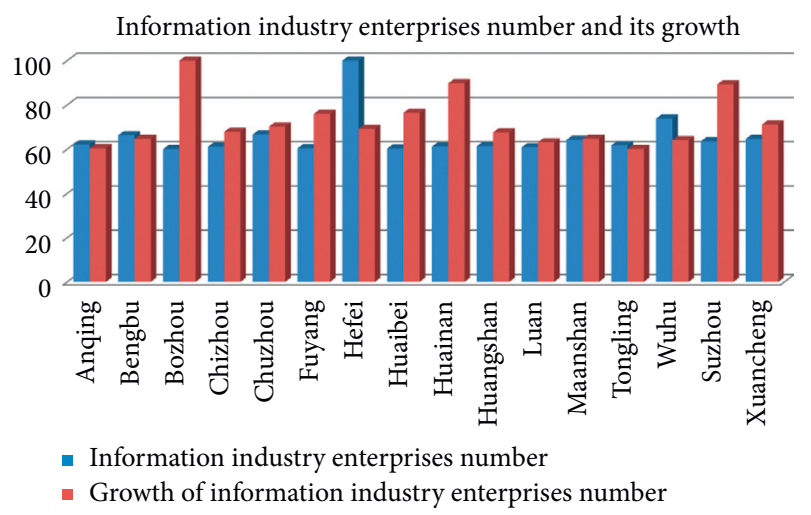

FIGURE 6: Information industry enterprises number and its growth.

Proportion of fixed assets investment in information industry in social fixed assets investment

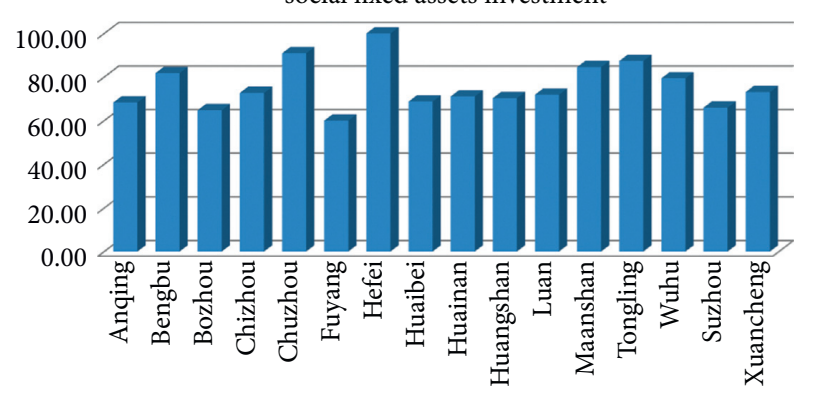

Figure 7: Proportion of fixed assets investment in information industry in social fixed assets investment.

standard implementation level of enterprise integration. Hefei has perfect information infrastructure for the integration of industrialization and industrialization, and the benefits of promoting industrial development by informatization are good. Hefei has a very rich and high level of science and technology education resources. It is the only national science and technology innovation pilot city in China. Compared with other cities, its technical force is much stronger. The comprehensive development of science, education, culture and health undertakings, convenient transportation and communication, and high level of urbanization are the supporting centers and links for the

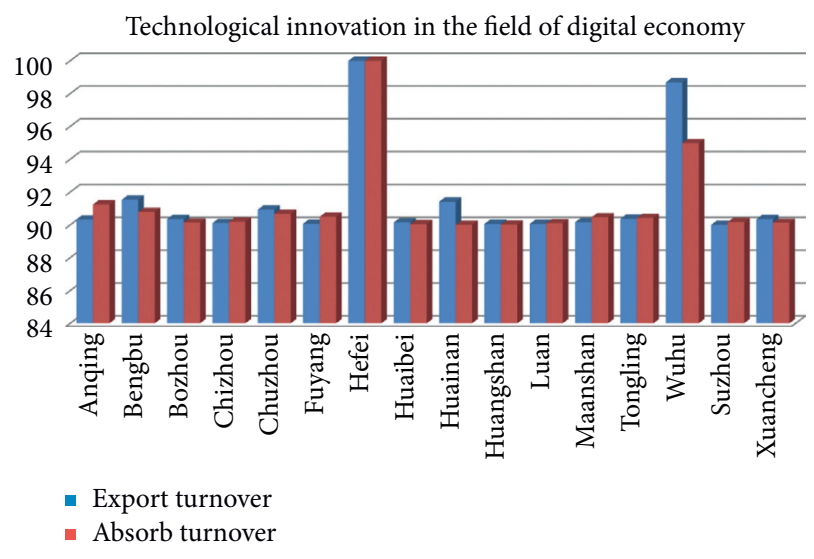

FIgURE 8: Technological innovation in the field of digital economy.

development of cities in Anhui Province. Due to the rich high-quality talent resources, it provides a strong guarantee for its rapid economic development. The industrial structure is relatively reasonable, and there are many industrial categories. Heavy industry and light industry have a certain proportion, which can produce good results through the convergence of capacity in the development process. There is little difference in the integration level of urbanization and urbanization in other cities, and there are some differences in the standard implementation level of integration of urbanization and urbanization. The standard implementation level of Northern Anhui, such as Suzhou and Huainan, is obviously lower than that of other regions.

As can be seen from Figure 10, Hefei and Wuhu are significantly ahead of other cities in the field of e-commerce. Huaibei and Tongling are backward in the province.

As can be seen from Figure 11, most cities such as Anqing, Bozhou, Hefei, Wuhu, Huangshan, Maanshan, and Xuancheng are in a good situation in the development of smart education. In terms of smart medical indicators, there is little difference among cities in Anhui Province. In terms of smart tourism indicators, Xuancheng and Huangshan are ahead of other cities. Relying on the unique tourism resources in the city, Xuancheng and Huangshan vigorously develop smart tourism to better promote the development of local tourism and further drive the development of regional economy. 
Merge together with informatization and industrialisation, standard implementation level

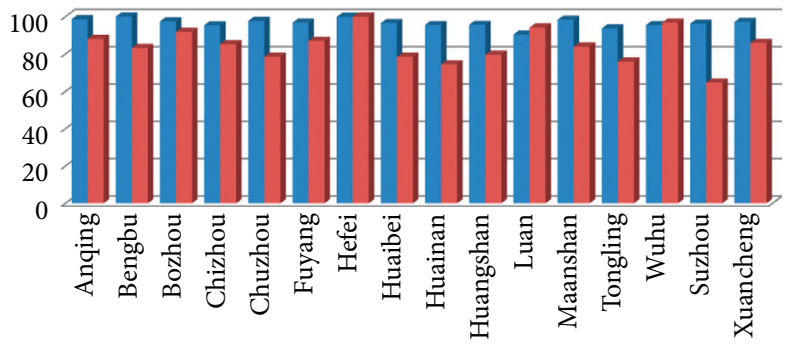

- Merge together with informatization and industrialisation

- Standard implementation level

FIgURE 9: Merge together with informatization and industrialization, standard implementation level.

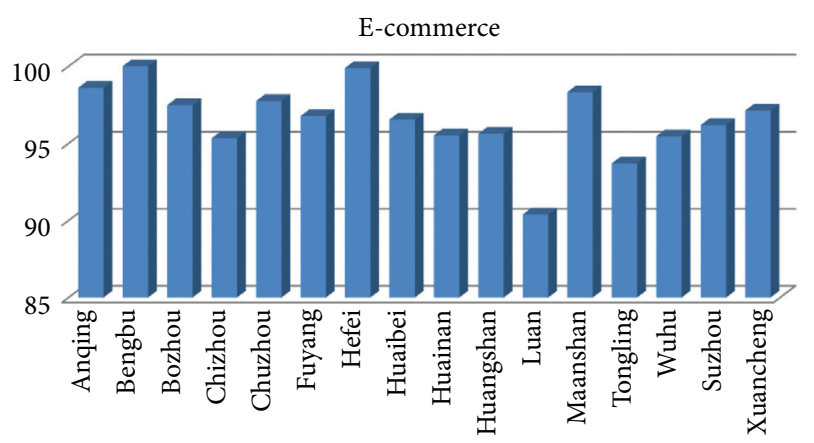

Figure 10: E-Commerce.

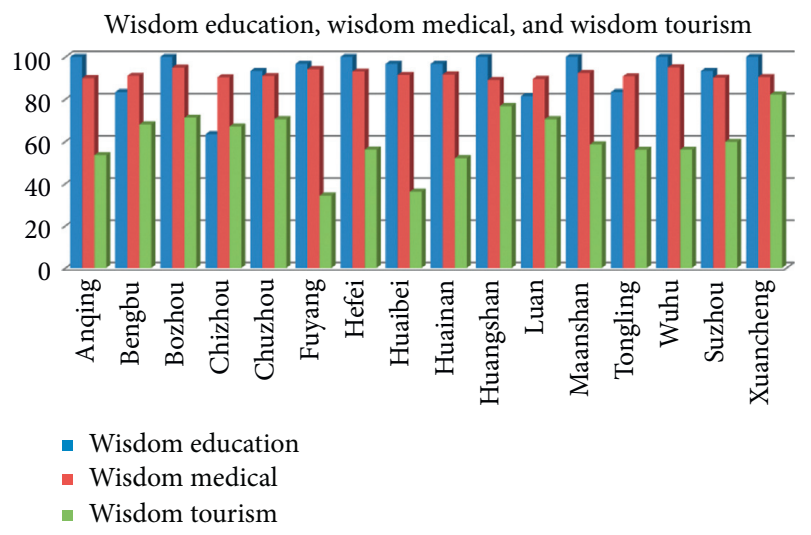

Figure 11: Wisdom education, wisdom medical, and wisdom tourism.

As can be seen from Figure 12, the information infrastructure construction of Hefei and Wuhu is relatively perfect in Anhui Province, while Huainan and Tongling are relatively backward.

According to the above index items, 16 cities in Anhui Province were evaluated, and the index items and comprehensive scores are shown. As can be seen from Figure 1, among the 16 cities in Anhui Province, Hefei has the most obvious effect in developing digital economy, followed by Wuhu, and Huaibei has the lowest score. Among them, Chuzhou, Xuancheng, and Maanshan scored less than 0.5

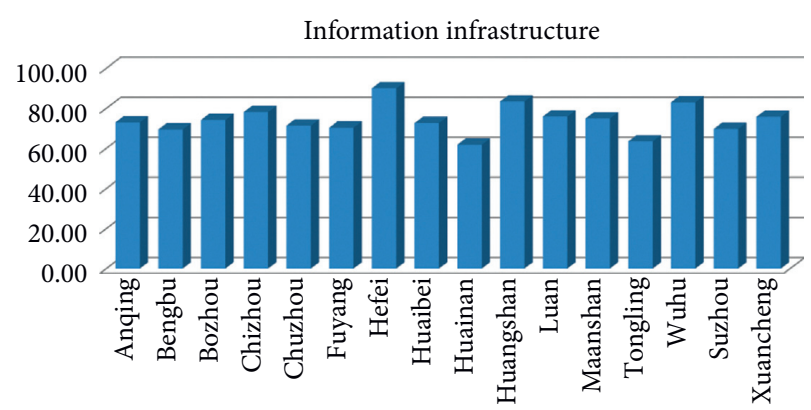

FIGURE 12: Information infrastructure.

points. From the statistical results, a total of 7 cities scored higher than the average (79.72), which shows that the development of digital economy in all cities of the province needs to be further enhanced, which is also consistent with the digital economy industrial policy release in 2018. From Figures 2-5, it can be seen that the income of electronic information manufacturing, software and information technology services, telecommunications, radio and television and satellite transmission services, and Internet-related services in Hefei, the provincial capital, is much higher than that in other cities, which is the core area of economic development in the province. In addition, some cities have zero scores in individual indicators, such as Fuyang and Huangshan in software and information technology service indicators, Huaibei in Internet mutual service indicators, which also shows that these cities are seriously underdeveloped in the software and Internet industry, and need to promote their development through the development of digital economy.

\section{Conclusion}

This study designs the index system of digital economy in Anhui Province, including 3 first level indexes and 20 second level indexes, and gives the weight composition of the first and second level indexes. According to the efficiency coefficient method, this study makes a statistical analysis of the digital economy of 16 cities in Anhui Province, including the average value, standard deviation, variance, kurtosis, skewness, and other information of the secondary indicators, and further analyzes the overall situation of the development of digital economy in Anhui Province. At present, the index system of digital economy only considers the level of city, and there is no statistical analysis on the situation of digital economy in each county. The next step is to study the index system of digital economy in each county.

\section{Data Availability}

The data used to support the findings of this study are included within the article.

\section{Conflicts of Interest}

The authors declare that there are no conflicts of interest. 


\section{Acknowledgments}

This work was supported by the National Natural Science Foundation of China (61976198), the Natural Science Research Key Project for Colleges and University of Anhui Province (KJ2019A0726), High Level Scientific Research Foundation for the Introduction of Talent of Hefei Normal University (2020RCJJ44), and the Anhui Province Key Laboratory of Big Data Analysis and Application Open Project.

\section{References}

[1] B. Kim, A. Barua, and A. B. Whinston, "Virtual field experiments for a digital economy: a new research methodology for exploring an information economy," Decision Support Systems, vol. 32, no. 3, pp. 215-231, 2002.

[2] B. Carlsson, "The digital economy: what is new and what is not?," Structural Change and Economic Dynamics, vol. 15, no. 3, pp. 245-264, 2004.

[3] R. L. Katz, S. Vaterlaus, P. Zenhäusern, and S. Suter, "The impact of broadband on jobs and the German economy," Intereconomics, vol. 45 , no. 1 , pp. 26-34, 2010.

[4] H. B. Zaman, A. H. Norsiah, A. Ahmad et al., "A visual measurement model on human capital and ICT dimensions of a knowledge society (KS) framework for Malaysia towards an innovative digital economy," in Proceedings of the Visual Informatics: Sustaining Research and Innovations-2nd International Visual Informatics Conference, Selangor, Malaysia, November 2011.

[5] V. D. W. Aryanto and A. A. Chrismastuti, "Model for digital economy in Indonesia," International Journal of Innovation in the Digital Economy, vol. 2, no. 2, pp. 39-55, 2011.

[6] L. Mocean and C. M. Pop, "Marketing recommender systems: a new approach in digital economy," Informatica Economica, vol. 16, no. 4, pp. 142-149, 2012.

[7] B. Beham, P. Drobnič, and S. Drobnč, "Who's got the balance? A study of satisfaction with the work-family balance among part-time service sector employees in five western European countries," The International Journal of Human Resource Management, vol. 23, no. 18, pp. 3725-3741, 2012.

[8] C. K. Georgiadis, E. Stiakakis, and A. R. Ravindran, "Editorial for the special issue: digital economy and E-commerce technology," Operational Research, vol. 13, no. 1, pp. 1-4, 2013.

[9] V. Turcan, A. Gribincea, and I. Birca, "Digital economy-a premise for economic development in the 20th century," Economy \& Sociology Theoretical \& Scientifical Journal, vol. 2, pp. 109-115, 2014.

[10] F. Zhao, J. Wallis, and M. Singh, "E-government development and the digital economy: a reciprocal relationship," Internet Research, vol. 25, no. 5, pp. 734-766, 2015.

[11] J. B. Liu, S. Wang, C. Wang, and S. Hayat, "Further results on computation of topological indices of certain networks," IET Control Theory \& Applications, vol. 11, no. 13, pp. 2065-2071, 2017.

[12] J. Itkonen, "How can we measure the economy in the digital era?," Economic Outlook, vol. 91, pp. 3-13, 2017.

[13] L. Haimeng, C. Fang, and S. Sun, "Digital inequality in provincial China," Environment \& Planning A, vol. 49, no. 10, pp. 2179-2182, 2017.

[14] E. V. Popov and K. A. Semyachkov, "Problems of economic security for digital society in the context of globalization," Economy of Region, vol. 14, no. 4, pp. 1088-1101, 2018.
[15] A. V. Todoru and V. Tselentis, "Digital technologies and the modernization of public administration," Quality-Access to Success, vol. 19, no. 165, pp. 73-78, 2018.

[16] N. Trusova, "Government socio-economic policy under the digital economy in the foreign countries and Russia," Economic Annals, vol. 180, no. 11-12, pp. 88-96, 2019.

[17] S. Andriy, K. Ganna, and S. E. Alexandru, "The analysis of the digital economy and society index in the EU," Baltic Journal of European Studies, vol. 9, no. 3, pp. 245-261, 2019.

[18] E. Brynjolfsson, A. Collis, W. E. Diewert, F. Eggers, and K. J. Fox, "GDP-B: accounting for the value of new and free goods in the digital economy," NBER Working Papers, Article ID 25695, 2019.

[19] J.-B. Liu and S. N. Daoud, "Number of spanning trees in the sequence of some graphs," Complexity, vol. 2019, Article ID 4271783, 22 pages, 2019.

[20] L. Mazelis, K. Lavrenyuk, and A. Krasko, "Fuzzy approach for the formation of an optimal portfolio of strategic projects to achieve regional development targets in the digital economy," International Journal of Technology, vol. 11, no. 6, pp. 11361147, 2020.

[21] Z. Bánhidi, I. Dobos, and A. Nemeslaki, "What the overall digital economy and society index reveals: a statistical analysis of the DESI EU28 dimensions," Regional Statistics, vol. 10, no. 2, pp. 46-62, 2020. 